\title{
Foreign Capital Inflow, Non-traded Intermediary, Urban Unemployment, and Welfare in a Small Open Economy: A Theoretical Analysis
}

\author{
SARBAJIT CHAUDHURI
}

\begin{abstract}
The paper attempts to analyse the implications of foreign capital inflow in a small open economy with a non-traded intermediary on the welfare and urban unemployment in a three-sector Harris-Todaro (1970) framework. The standard immiserising result of a foreign capital inflow has been found to be valid when the non-traded intermediary is solely used in the protected import-competing sector. However, if the export sector too uses the intermediary, the economy may experience an improvement in its welfare and a reduction in the urban unemployment level.
\end{abstract}

\section{INTRODUCTION}

The effects of inflow of foreign capital in the developing countries have been investigated intensively by both trade and development theorists. Brecher and Alejandro (1977) have analysed the welfare effects of foreign capital inflow in a two-commodity, two-factor full employment model; and Khan (1982) has considered a mobile capital Harris-Todaro model with urban unemployment. The important result, common to both, is the following. The inflow of foreign capital with full repatriation of its earnings is necessarily immiserising if the importcompeting sector is capital-intensive and is protected by a tariff. However, in the absence of any tariff, the foreign capital inflow with full repatriation of its earnings does not affect welfare. Here welfare is defined as a positive function of national income.

In the literature, the Brecher-Alejandro proposition has also been reexamined in terms of three-sector models. The third sector may either be a dutyfree zone (DFZ) (sometimes called 'foreign enclave') as in the works of Beladi and Marjit $(1992,1992 a)$ or it may be regarded as an urban informal sector as in the works of Grinols (1991); Chandra and Khan (1993) and Gupta (1997). The work

Sarbajit Chaudhuri is Reader in the Department of Economics, University of Calcutta.

Author's Note: The author is indebted to an anonymous referee of this journal for his/her constructive comments on an earlier version of the paper. However, the usual disclaimer applies. 
of Beladi and Marjit (1992) is a simple three-sector extension of the HeckscherOhlin-Samuelson framework, where the third sector, the DFZ, uses sector-specific foreign capital that is foreign-owned. They have shown that with full-repatriation of foreign capital income, growth in the foreign capital may lead to immiserising growth in the presence of tariff-distortion even if the foreign capital is employed in the export sector. This generalises the main result in the existing literature, which primarily focuses on foreign capital movement in the protected sector of the economy.

On the other hand, there are some theoretical papers in the literature, which show that the inflow of foreign capital may be welfare-improving in a developing country in some special cases even in the presence of tariff distortion. For example, Chaudhuri and Mukherjee (2002) show that in a production structure appropriate for a developing economy, there may be cases where one is able to derive a result relating to foreign capital inflow which is counterintuitive to the conventional wisdom. They have developed a three-sector general equilibrium model with two informal sectors, where there is complete mobility of labour between these two sectors, and have assumed a positive relationship between wage income and labour's efficiency. In this scenario, the possibilities of welfare improvement have been explored with simultaneous increases in labour and capital endowments of the economy, where the latter is caused by an inflow of foreign capital while the former is the result of a consequent positive effect on labour's efficiency of an increase in the labour incomes arising from the reallocation of labour among the different sectors of the economy. The paper shows that in the presence of labour market distortions, foreign capital inflow may be desirable both in the presence and absence of tariff protection due to its favourable impact on welfare. This result cannot be found in earlier papers based on the Harris-Todaro framework with labour market distortion. Chaudhuri and Mukhopadhyay (2002) have also reached the same broad conclusion in terms of a two-sector general equilibrium model with an informal sector. Besides, in Chaudhuri and Mukhopadhyay (2002) it is shown that the counterintuitive result relating to foreign capital inflow is independent of the trade pattern of the relevant country, and that the existence of distortion in the labour market is a necessity for any foreign capital inflow to be welfare-improving in a tariff-distorted developing economy. The validity of the Wage efficiency hypothesis is, on the contrary, neither necessary nor sufficient to derive gainful effects from foreign capital. The latter, coupled with labour market imperfection, however, fortifies the possibility of welfare improvement.

If one considers a production structure, which contains an intermediate goodproducing sector, an inflow of foreign capital may be welfare-improving, as well. Marjit and Beladi (1996) have analysed such a case. They have studied the impact of an inflow of foreign capital in the internationally traded intermediate good-producing sector in the context of a $3 \times 3$ full-employment model and found out the conditions under which a foreign capital inflow would be welfare-improving. 
Recently, there has been a welcoming attitude in many developing countries to provide several incentives for the purpose of attracting foreign capital into infrastructure. The term 'infrastructure' generally refers to the physical framework of facilities through which goods and services are provided to the public. Its linkages to the economy are multiple and complex. Infrastructure affects production and consumption directly, creates spillover effects in every sector of the economy, and generally requires huge investments. In India, foreign direct investment (FDI) inflows from 1991-99 have added up to $\$ 60$ billion, which is amongst the highest in the world. The cumulative FDI (from 1991 to the end of 1999) adds up to over $\$ 59.7$ billion (including GDRs). The FDI in infrastructure has been around \$30 billion since 1991. The sector-wise break-up of foreign direct investment proposals approved by the Government of India between 1991 and 1999 is given in the following table.

\begin{tabular}{lc} 
Sector-wise Break-up of FDI Approved (1991 to 1999) \\
\hline Sector & Percentage \\
\hline Fuels & $32.11 \%$ \\
Telecommunications & $17.83 \%$ \\
Transportation & $6.85 \%$ \\
Service Sector & $6.32 \%$ \\
Metallurgical & $6.00 \%$ \\
Electrical Equipment & $5.14 \%$ \\
Food Processing & $4.49 \%$ \\
Hotels and Tourism & $1.89 \%$ \\
Others & $19.27 \%$ \\
\hline
\end{tabular}

Source: Indian Ministry of Commerce.

During 1999 (Jan.-Dec.), FDI inflows (including GDRs) were 26 percent higher at Rs 16,867.79 crore as against Rs 13,339.84 crore during 1998 (Jan.-Dec.). ${ }^{1}$

Infrastructure is basically a sector producing non-traded intermediaries. Unfortunately, economists have so far paid little attention to analyse the effects of inflow of foreign capital in a small open economy with a non-traded intermediary.

The present paper attempts to analyse the implications of foreign capital inflow in a small open economy with a non-traded intermediary for the welfare and urban unemployment in a Harris-Todaro (1970) framework. It has been found that an inflow of foreign capital reduces the welfare and raises the urban unemployment of labour if the non-traded intermediate good is only used by the protected urban import-competing sector. On the contrary, when the export sector too uses the nontraded intermediary, the result on urban unemployment may be the reverse, and also

${ }^{1}$ All this information may be obtained from the Website: <www.diehardindian.com>. 
the economy may experience an improvement in its welfare under a reasonable necessary and sufficient condition. Thus, the welfare effect of an inflow of foreign capital in the presence of a non-traded intermediary crucially hinges on which sector uses this input and to what extent.

\section{THE MODEL}

We consider a small open monetised dual economy, which is broadly divided into an urban sector and a rural sector. The urban sector is subdivided into two subsectors so that, on the whole, we have three sectors in the economy. The first sector (sector $Z$ ) within the urban sector is the tariff-protected import-competing manufacturing sector that produces an intermediate input ${ }^{2}$ (e.g., fertiliser, pesticides, or pump sets for irrigation) using labour, capital, and a non-traded intermediate input. The second sector ( $Y$ sector) within the urban sector produces the non-traded intermediary with the help of labour and capital. The rural sector ( $X$ sector) produces its product (the export commodity of the economy) with labour, fertiliser ${ }^{3}$ (the product of sector $Z$ ), and the non-traded intermediary. ${ }^{4}$ Although fertiliser is domestically produced, the level of production fails to exhaust the entire domestic demand so that the residual amount has to be imported at the internationally given price. The total stock of capital of the economy consists of both domestic and foreign capital, and these are perfect substitutes ${ }^{5}$ of each other. Capital is mobile between the two urban sectors. ${ }^{6}$ The rural wage rate, $W$, is flexible while the wage rate in the two urban sectors, $W^{*}$, is exogenously given with $W^{*}>W$. This wage differential leads to migration of labour from the rural to the urban sector. Owing to our small open economy assumption, we consider prices of fertiliser and the rural product to be given internationally. However, as sector $Y$ produces a non-traded intermediary, its price is endogenously determined. Production functions exhibit constant returns to scale with diminishing marginal productivity to each factor.

The following symbols will be used in the equations.

$a_{K i}=$ capital-output ratio in the ith sector, $i=Y, Z$;

$a_{L i}=$ labour-output ratio in the ith sector, $i=X, Y, Z$;

$a_{Z X}=$ amount of $Z$ required to produce one unit of $\operatorname{good} X$;

${ }^{2,3}$ One can check that the qualitative results of this paper remain unaffected if an alternative production structure is considered where the import-competing sector produces a final commodity and the export sector uses capital directly in its production. Detailed mathematical proofs may be obtained from the author on request.

${ }^{4}$ It may be electricity to operate pump sets for irrigation purposes, roads to facilitate marketing of agricultural products, etc.

${ }^{5}$ This simplified assumption has been made in Brecher and Alejandro (1977); Khan (1982); Grinols (1991); Chandra and Khan (1993); Gupta (1997), etc. However, in the papers of Beladi and Marjit (1992, 1992a) and Marjit and Beladi (1996) foreign capital has been treated differently from domestic capital and these two types of capital are not engaged in the same sector of the economy.

${ }^{6}$ Note that sector $X$ does not use capital directly. 
$a_{Y i}=$ amount of $Y$ required to produce one unit of output in the $i$ th sector, $i=X$, $Z$;

$P_{i}=$ world price of the $i$ th good, $i=X, Z$;

$t=a d$ valorem rate of tariff on the import of $Z$;

$P_{Z \cdot(1+t)}=$ domestic or tariff-inclusive price of $Z$;

$P_{Y}=$ price of the non-traded intermediary (determined endogenously);

$W=$ wage rate of labour in the $X$ (rural) sector;

$W^{*}=$ unionised wage rate of labour in the two urban sectors;

$r=$ return to capital;

$L=$ given endowment of labour;

$K_{D}=$ domestic capital stock of the economy;

$K_{F}=$ foreign capital stock;

$K=$ aggregate capital stock of the economy, with $K=K_{D}+K_{F}$;

$L_{U}=$ level of unemployment of labour in the urban sector;

$M=$ volume of imports of $Z$;

$I=$ national income at world prices;

$\lambda_{j i}=$ proportion of the $j$ th input employed in the $i$ th sector of the economy, $j=L, K, Y$; and, $i=X, Y, Z$;

"^" = proportional change.

A general equilibrium of the system is represented by the following set of equations:

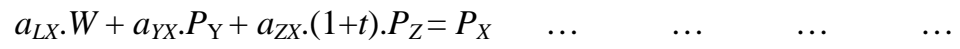

$$
\begin{aligned}
& \begin{array}{lllllll}
a_{L Y} \cdot W^{*}+a_{K Y} \cdot r=P_{Y} & \ldots & \ldots & \ldots & \ldots & \ldots
\end{array}
\end{aligned}
$$

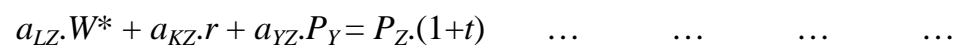

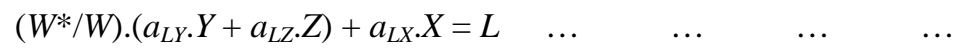

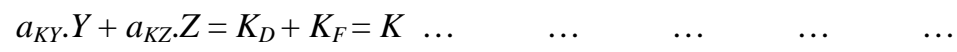

$$
\begin{aligned}
& \begin{array}{llllllll}
a_{Y X} \cdot X+a_{Y Z} \cdot Z=Y & \ldots & \ldots & \ldots & \ldots & \ldots & \ldots
\end{array} \\
& \begin{array}{llllll}
a_{L Y} \cdot Y+a_{L Z} \cdot Z+a_{L X} \cdot X+L_{U}=L & \ldots & \ldots & \ldots & \ldots
\end{array} \\
& \begin{array}{lllllll}
M=a_{Z X} \cdot X-Z & \ldots & \ldots & \ldots & \ldots & \ldots & \ldots
\end{array}
\end{aligned}
$$

Equations (1-3) denote the three competitive equilibrium conditions. Equations (5) and (6) denote the full-employment conditions for capital and the nontraded intermediary, $Y$. Equation (4) is the Harris-Todaro rural-urban migration equilibrium condition. The labour endowment equation is given by (7). Finally, (8) measures the volume of import of $Z$.

We have eight independent equations to solve for eight unknowns- $W, r, P_{Y}$, $X, Y, Z, M$ and $L_{U}$. We should note that the system possesses the decomposition 
property. The three unknown factor prices, $W, r$ and $P_{Y}$, are determined from Equations (1-3) independent of the factor endowments. Once factor prices are known, the factor-coefficients are also determined. Then from Equations (4-6), $X, Y$, and $Z$ are obtained. The volume of import of fertiliser (the traded intermediary, $Z$ ) is found from (8) once $X$ and $Z$ are known. Finally, from Equation (7) the level of urban unemployment, $L_{U}$, is determined.

Before going into comparative statics, it is important to mention that our measure of welfare in this small open economy is national income at world prices, $I$, and it is expressed as follows. ${ }^{7}$

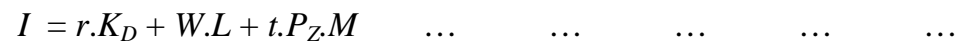

$r . K_{D}$ is the income from domestic capital stock after full repatriation of foreign capital income. W.L is the aggregate wage income of the workers in an economy with Harris-Todaro type of migration mechanism. t.P.M is the amount of tariff revenue earned from the import of fertiliser.

\section{COMPARATIVE STATIC EXERCISES}

We now consider the effects of an inflow of foreign capital in this small open economy. Owing to an inflow of foreign capital, $K_{F}$, the size of the capital stock of the economy swells up. The factor prices remain unaffected due to the decomposition property of the system, but the product mix changes. To see how the levels of output of the different sectors change after totally differentiating Equations (4-6) and using the envelope conditions, we obtain the following expressions.

$$
\begin{aligned}
& \lambda_{L X} \cdot \hat{X}+\left(W^{*} / W\right) \cdot \lambda_{L Y} \cdot \hat{Y}+\left(W^{*} / W\right) \cdot \lambda_{L Z} \cdot \hat{Z}=0 \quad \ldots \quad \ldots \quad \ldots \\
& \begin{array}{lllllll}
\lambda_{K Y} \cdot \hat{Y}+\lambda_{K Z} \cdot \hat{Z}=\hat{K} & \ldots & \ldots & \ldots & \ldots & \ldots & \ldots
\end{array} \\
& \begin{array}{lllllll}
\lambda_{Y X} \cdot \hat{X}+\lambda_{Y Z} \cdot \hat{Z}=\hat{Y} & \ldots & \ldots & \ldots & \ldots & \ldots & \ldots
\end{array}
\end{aligned}
$$

(Note that $\hat{L}=0$ as the labour endowment does not change.)

Using (12) Equations (10) and (11) may be rewritten as

$$
\begin{aligned}
& \left.\left\{\lambda_{L X}+\left(W^{*} / W\right) \cdot \lambda_{L Y} \cdot \lambda_{Y X}\right)\right\} \cdot \hat{X}+\left\{\left(W^{*} / W\right) \cdot\left(\lambda_{L Z}+\lambda_{Y Z} \cdot \lambda_{L Y}\right)\right\} \cdot \hat{Z}=0 \\
& \left(\lambda_{K Y} \cdot \lambda_{Y X}\right) \cdot \hat{X}+\left(\lambda_{K Z}+\lambda_{K Y} \cdot \lambda_{Y Z}\right) \cdot \hat{Z}=\hat{K} \quad \ldots \quad \ldots \quad \ldots
\end{aligned}
$$
expressions.

Now solving (10.1) and (11.1) by Cramer's rule we get the following

$$
\hat{X}=-\left\{\left(W^{*} / W\right) \cdot\left(\lambda_{L Z}+\lambda_{Y Z} \cdot \lambda_{L Y}\right) /|\lambda|\right\} . \hat{K} \quad \ldots \quad \ldots \quad \ldots
$$

${ }^{7}$ If the import-competing sector produces a final commodity, the expression for the national income at international prices has to be replaced by the following equation: $I=r . K_{D}+W . L-t . P_{Z} . Z$. Here, t. $P_{Z} . Z$ measures the cost of tariff-protection of the import-competing sector. 


$$
\hat{Z}=\left[\left\{\lambda_{L X}+\left(W^{*} / W\right) \cdot \lambda_{L Y} \cdot \lambda_{Y X}\right\} /|\lambda|\right] \cdot \hat{K} \quad \ldots \quad \ldots . \quad \ldots \quad \ldots
$$

where $|\lambda|=\left[\left\{\lambda_{L X}+\left(W^{*} / W\right) \cdot \lambda_{L Y} \cdot \lambda_{Y X}\right\} \cdot\left(\lambda_{K Z}+\lambda_{K Y} \cdot \lambda_{Y Z}\right)-\left(W^{*} / W\right)\right.$.

$$
\left.\left(\lambda_{L Z}+\lambda_{Y Z} \cdot \lambda_{L Y}\right) \cdot \lambda_{K Y} \cdot \lambda_{Y X}\right]
$$

$$
\begin{aligned}
& >(<) 0 \text { iff }\left[\left(\lambda_{K Z}+\lambda_{K Y} \cdot \lambda_{Y Z}\right) /\left(W^{*} / W\right) \cdot\left(\lambda_{L Z}+\lambda_{Y Z} \cdot \lambda_{L Y}\right)\right]>(<)\left[\left(\lambda_{K Y} \cdot \lambda_{Y X}\right) /\right.
\end{aligned}
$$

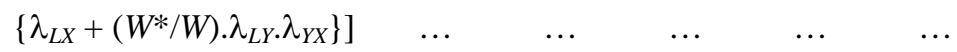

So $|\lambda|>(<) 0$ if and only if the vertically integrated import-competing sector is more (less) capital-intensive vis-à-vis the vertically integrated export sector.

Also using (12), (13.1) and (13.2) one can write

$$
\hat{Y}=\left[\left\{\lambda_{Y Z} \cdot \lambda_{L X}-\left(W^{*} / W\right) \cdot \lambda_{Y X} \cdot \lambda_{L Z}\right\} /|\lambda|\right] . \hat{K} \quad \ldots \quad \ldots \quad \ldots
$$

Now, differentiating Equation (9) with respect to $K$ we get

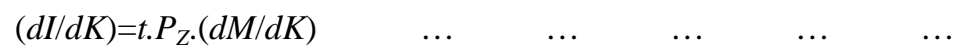

Differentiating (8), using (13.1) and (13.2), and simplifying we get

$$
\begin{aligned}
& (d M / d K)=-(1 / K .|\lambda|) \cdot\left[a_{Z X} \cdot X \cdot\left(W^{*} / W\right) \cdot\left(\lambda_{L Z}+\lambda_{Y Z} \cdot \lambda_{L Y}\right)+\right.
\end{aligned}
$$

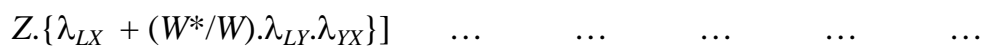

$$
\begin{aligned}
& \text { So }(d M / d K)>(<) 0 \text { iff }|\lambda|<(>) 0 \text {. From (9.1) it now follows that } \\
& (d I / d K)>(<) 0 \text { if and only if }|\lambda|<(>) 0 \text {. }
\end{aligned}
$$

This establishes the following proposition.

PROPOSITION 1: An inflow of foreign capital is welfare-improving if and only if $|\lambda|<0 .^{8}$

It is fairly straightforward to explain proposition 1 verbally. Sector $X$ does not use capital in its production directly. But, indirectly, capital is used in this sector, as production of $X$ requires the non-traded intermediary, which uses capital. The nontraded input, $Y$, is used in both sectors $X$ and $Z$. An increase in the size of capital stock of the economy due to an inflow of foreign capital cannot affect the factor prices, and hence the $a_{j i}$ s. However, sector $X$ expands and the import-competing sector ( $Z$ sector) contracts due to the Rybczynski effect if and only if the vertically integrated export sector is more capital-intensive than the import-competing sector. As factor prices do not change, the aggregate domestic factor income, $\left(W . L+r . K_{D}\right)$, also does not change due to a foreign capital inflow. As sector $X$ expands, it requires a larger amount of fertiliser (the traded intermediary) in its production. But the

${ }^{8}$ It is obvious that a non-traded intermediary like a power project is much more capital-intensive than a fertiliser industry. So, $|\lambda|$ may be negative if the non-traded intermediate good-producing sector is much more capital-intensive vis-à-vis the protected import-competing sector and a lion's share of the nontraded intermediary is used in the export sector. 
domestic production of commodity $Z$ has fallen. The net result would be an increase in the volume of import of the traded intermediary, $M$. The national income measured at world prices, $I$, goes up due to an increase in tariff revenue.

Differentiating (7) the following expression may be obtained.

$$
\lambda_{L X} \cdot \hat{X}+\lambda_{L Y} \cdot \hat{Y}+\lambda_{L Z} \cdot \hat{Z}+\lambda_{L U} \cdot \hat{L}_{U}=0
$$

Using (13.1), (13.2) and (13.3), and after simplification, the above expression may be rewritten as

$$
\lambda_{L U} \cdot \hat{L}_{U}=(\hat{K} /|\lambda|) \cdot\left[\left\{\left(W^{*}-W\right) / W\right\} \cdot \lambda_{L X} \cdot\left(\lambda_{L Z}+\lambda_{Y Z} \cdot \lambda_{L Y}\right)\right] \quad \ldots \quad \ldots
$$

From (16) it follows that $\hat{L}_{U}<0$ when $\hat{K}>0$ iff $|\lambda|<0$. So the following proposition can now be established.

PROPOSITION 2: The level of urban unemployment decreases owing to a foreign capital inflow if and only if $|\lambda|<0$.

Proposition 2 can be easily explained in economic terms. An inflow of foreign capital changes the output composition of the economy. When the vertically integrated urban sector is less capital-intensive than the vertically integrated rural sector, the latter sector expands while the urban sector altogether contracts following a Rybczynski effect. As the system possesses the decomposition property, factor coefficients do not change. As a consequence, the rural sector (urban sector) now employs more (less) labour than before. The expected urban sector wage rate for a prospective rural migrant falls, leading to a reverse migration to the rural sector. Thus iff $|\lambda|<0$, the aggregate level of employment in the economy increases, thereby reducing the urban unemployment level.

\subsection{Two Special Cases}

We have so far analysed the general case where the non-traded intermediary is used in both the export- and import-competing sectors of the economy. However, one can explore the following two cases, which can be derived as special cases from this general framework.

Special Case I: We shall first consider the case where the non-traded intermediary is used only in the import-competing sector. In this case, we must have $a_{Y X}, \lambda_{Y X}=0, a_{Y Z}>0$ and $\lambda_{Y Z}=1$. From (14) it is easy to check that $|\lambda|=\lambda_{L X} \cdot\left(\lambda_{K Z}\right.$ $\left.+\lambda_{K Y}\right)=\lambda_{L X}>0$. Now from (13.1) - (13.3) and (15) it, therefore, follows that $\hat{X}<$ 0 ; $\hat{Y}, \hat{Z}>0$; and, $(d M / d K)<0$. So from (9.1), it trivially follows that $(d I / d K)<0$. Again from (16), one finds that $\hat{L}_{U}>0$ when $\hat{K}>0$. The following proposition follows immediately. 
PROPOSITION 3: An inflow of foreign capital with full repatriation of foreign capital income reduces the welfare of the economy and raises the urban unemployment of labour when the non-traded intermediary is only used in the protected import-competing sector.

The intuitive explanations of the above results are fairly straightforward. In this case, the non-traded intermediary, $Y$, is a specific input in the production of the import-competing sector $Z$. Hence both sectors $Y$ and $Z$, which use capital in production expand. Here, we should note that the usual Rybczynski effect does not work because of the sector-specificity of $Y$ in the $Z$ sector. The aggregate employment of labour in these two urban sectors also grows, which pushes up the expected urban wage rate. As a consequence, more and more workers migrate from the rural to the urban sector. The $X$ sector shrinks due to a shortage of labour in the rural sector but the urban unemployment level rises since the new migrants outnumber the new vacancies created in the urban sector. As factor prices do not change, the aggregate domestic factor income, $\left(W . L+r . K_{D}\right)$, also does not change. The volume of import of the traded intermediary, $M$, decreases as $X$ falls and $Z$ rises. The national income measured at world prices, $I$, goes down due to a fall in tariff revenue.

Special Case II: We now consider the other extreme case where the nontraded intermediary is used solely in the export sector. In this case, we have $a_{Y X}>0$, $\lambda_{Y X}=1, a_{Y Z}, \lambda_{Y Z}=0$. From (14) one can verify that $|\lambda|=\left[\left\{\lambda_{L X}+(W * / W) \cdot \lambda_{L Y}\right\} \cdot \lambda_{K Z}\right.$ $\left.-\left(W^{*} / W\right) \cdot \lambda_{L Z} \cdot \lambda_{K Y}\right]$. So $|\lambda|<0$ iff $\left[\lambda_{K Z} /\left(W^{*} / W\right) \cdot \lambda_{L Z}\right]<\left[\lambda_{K Y} /\left\{\lambda_{L X}+\left(W^{*} / W\right) \cdot \lambda_{L Y}\right\}\right]$, i.e., if the vertically integrated export sector is more capital-intensive than sector $Z$.

Now from (13.1) - (13.3) and (15) it, therefore, follows that $\hat{X}, \hat{Y}>0 ; \hat{Z}<$ 0 ; and, $(d M / d K)>0$ if and only if $|\lambda|<0$. Then from (9.1) and (16) one finds that $(d I / d K)>0$ and $\hat{L}_{U}<0$ when $\hat{K}>0$ under the necessary and sufficient condition that $|\lambda|<0$. The above results can be presented in the form of the following proposition.

PROPOSITION 4: When the non-traded intermediary is solely used in the export sector of the economy, an inflow of foreign capital with full repatriation of foreign capital income improves the welfare of the economy and lowers the urban unemployment of labour if and only if the protected import-competing sector is less capital-intensive than the vertically integrated export sector.

We explain Proposition 4 as follows. Here sector $X$ uses capital indirectly through the use of $Y$ in production. Sectors $Y$ and $X$ expand and sector $Z$ contracts owing to an inflow of foreign capital following a Rybczynski effect iff $|\lambda|<0$. Aggregate employment in the urban sector $\left(a_{L Y} . Y+a_{L Z} \cdot Z\right)$ goes down when $Y$ increases and $Z$ decreases if and only if $|\lambda|<0$. If this happens, the expected urban wage rate falls and a reverse migration takes place, which results in a decrease in the urban unemployment level. The expanding rural $(X)$ sector now absorbs a larger 
number of workers than before. On the other hand, the volume of imports of the traded intermediary increases as sector $X$ expands and sector $Z$ contracts. The aggregate domestic factor income does not change as factor prices do not change. However, the national income at international prices goes up due to an expansionary tariff revenue effect.

\section{CONCLUDING REMARKS}

In this paper, we have analysed the effects of an inflow of foreign capital on the welfare and urban unemployment of labour in a tariff-distorted small open economy in the presence of a non-traded intermediary. Our analysis is based on the Harris-Todaro (1970) framework. The protected import-competing sector produces an essential input for the rural sector. The non-traded intermediary may be used in either or both of the other two sectors. In this scenario, an inflow of foreign capital with full repatriation foreign capital income unambiguously lowers the welfare of the economy and raises the level of urban unemployment of labour if the non-traded intermediary is entirely used in the protected import-competing sector. However, the paper shows that the economy may experience an improvement in its welfare and a reduction in the urban employment due to a foreign capital inflow when the sector producing the non-traded intermediary is sufficiently capital-intensive relative to the import-competing sector and a sufficiently large amount of the output of the former is used in the export sector of the economy. These results are important because they challenge the standard immiserising result of foreign capital inflow in a small open economy, have been derived in the context of an economy with a highly capital-intensive non-traded intermediary like infrastructure, and especially because there is a (recent) welcoming attitude in many developing countries to attract foreign capital into such sectors.

\section{REFERENCES}

Beladi, H., and S. Marjit (1992) Foreign Capital and Protectionism. Canadian Journal of Economics 25, 233-38.

Beladi, H., and S. Marjit (1992a) Foreign Capital, Unemployment and National Welfare. Japan and the World Economy 4, 311-17.

Brecher, R. A., and C. F. Diaz Alejandro (1977) Tariffs, Foreign Capital and Immiserising Growth. Journal of International Economics 7, 317-22.

Chandra, V., and M. A. Khan (1993) Foreign Investment in the Presence of Informal Sector. Economica 60, 79-103.

Chaudhuri, S., and U. Mukherjee (2002) Removal of Protectionism, Foreign Investment and Welfare in a Model of Informal Sector. Japan and the World Economy 14:1, 101-16.

Chaudhuri, S., and U. Mukhopadhyay (2002) Economic Liberalisation and Welfare in a Model with an Informal Sector. The Economics of Transition 10:1, 143172. 
Grinols, E. L. (1991) Unemployment and Foreign Capital: The Relative Opportunity Cost of Domestic Labour and Welfare. Economica 57, 107-21.

Gupta, M. R. (1997) Foreign Capital and the Informal Sector: Comments on Chandra and Khan. Economica 64, 353-63.

Harris, J. R., and M. P. Todaro (1970) Migration, Unemployment and Development: A Theoretical Analysis. American Economic Review 60, 126-42.

Khan, M. A. (1982) Tariffs, Foreign Capital and Immiserising Growth with Urban Unemployment and Specific Factors of Production. Journal of Development Economics 10, 245-56.

Marjit, S., and H. Beladi (1996) Protection and Gainful Effects of Foreign Capital. Economics Letters 53. 